\title{
Comparison of Anterolateral Thigh and Radial Forearm Free Flaps in Head and Neck Reconstruction
}

\author{
CARLO M. ORANGES, BARBARA LING, MATHIAS TREMP, RETO WETTSTEIN, \\ DANIEL F. KALBERMATTEN and DIRK J. SCHAEFER
}

Department of Plastic, Reconstructive, Aesthetic, and Hand Surgery, Basel University Hospital, Basel, Switzerland

\begin{abstract}
Background: The radial forearm flap (RFF) and the anterolateral thigh flap (ALT) are commonly used for the reconstruction of head and neck soft-tissue defects. The aim of the study was to investigate and compare the surgical outcomes, complications and systemic condition of the patient after reconstruction of extensive head and neck defects with ALT or RFF following cancer extirpation. Patients and Methods: Between August 2011 and November 2013, a total of 36 patients affected by head and neck cancer $(31$ males and five females; mean age $=64.7$ years, range $=40-86$ years) underwent microsurgical reconstruction with $29 \mathrm{RFF}$ and 10 ALT procedures. The surgical outcomes and complications among these two groups were retrospectively analyzed. Results: The success rate was $97 \%$ for the RFF group and $90 \%$ for the ALT group, with one total flap loss in each group. Donor-site complications occurred in $6 \%$ of the RFF group and in $7 \%$ of the ALT group. Seven RFF-treated patients (24\%) and two treated with ALT (20\%) experienced systemic complications. Statistical analysis confirmed no significant difference between the two groups regarding the variables investigated $(p>0.05)$. Conclusion: In our experience, $A L T$ and RFF demonstrated analogous practicability and reliability for the reconstruction of head and neck soft-tissue defects, with similar local and systemic complications and donor-site morbidity rates.
\end{abstract}

Several sites for procurement of free flaps have been proposed for the reconstruction of soft-tissue defects after head and neck cancer extirpation. However, these defects

This article is freely accessible online.

Correspondence to: Dirk J. Schaefer, MD, Department of Plastic, Reconstructive, Aesthetic, and Hand Surgery, Basel University Hospital, Spitalstrasse 21, 4031 Basel, Switzerland. Tel: +41 612652525, Fax: +41612657301, e-mail: dirk.schaefer@usb.ch

Key Words: Head and neck cancer, free-flap transfer, reconstructive surgery, anterolateral thigh flap, radial forearm flap. have most commonly been reconstructed using radial forearm (RFF) and anterolateral thigh (ALT) flaps (1-4).

Since its introduction, the RFF has become particularly popular and accepted worldwide for the reconstruction of tongue and intraoral defects (5-8). The advantages offered by RFF include a thin texture, which facilitates folding, and an easy harvesting procedure; however, the dissection of the RFF implies the sacrifice of a major blood vessel to the hand, and the wound at the donor site often requires to be closed with a skin graft (4).

The clinical indications for using the ALT in soft-tissue head and neck reconstruction have recently increased (9). This flap indeed allows the transfer of different tissues with large amounts of skin and subcutaneous fat tissue of adjustable thickness, with a vascular pedicle of suitable length and relatively large-diameter vessels, and low donorsite morbidity (9).

Several studies analyzed and compared the two flap sources (4, 8-11). However, to our knowledge, a systematic analysis considering all the variables related to the reconstruction has not been performed. This study investigated and compared the outcomes in terms of free-flap survival and complications in the reconstructed area, morbidity of the donor site, and systemic conditions of the patient after reconstruction of head and neck defects with ALT or RFF.

\section{Patients and Methods}

Between August 2011 and November 2013, 36 patients affected by early (stage I-II) or advanced (stage III-IV) head and neck cancer were treated at the Department of Plastic, Reconstructive, Aesthetic and Hand Surgery, University Hospital Basel. Patients underwent composite resection, with excision of the primary tumor, including ipsilateral or bilateral neck dissection and microvascular flap reconstruction. Thirty-nine free-flap procedures (ALT or RFF) were performed to reconstruct the surgical defects. Patients were divided into two groups according to microsurgical reconstruction: ALT group $(n=10)$ and RFF group $(n=29)$.

Analysis of the following demographic and clinical variables was conducted for each group: patient sex and age, underlying disease according to the American Society of Anesthesiologists score (ASA) (12), pathological diagnosis, recipient site, previous radiation therapy. 
The microsurgical success rate, considered as flap survival, was analyzed and compared between the two groups. Complications were classified into donor-site, free-flap, and systemic complications according to Classen and Ward $(13,14)$. Analysis of donor-site complications included seroma, hematoma, infection, dehiscence, congestion, and skin graft loss, while systemic complications included postoperative comorbidities, pulmonary edema, postoperative hypertension and sepsis. Free-flap complications were divided into major, if needing surgical re-exploration, or minor, if not. The number of patients who developed donor-site, free-flap and systemic complications were recorded and compared between the groups.

Chi-square analysis with Fisher's exact test was performed to assess the relationship between surgical technique, outcomes and complications. Statistical analyses were performed for all tests using GraphPad Prism version 5.00 for Windows (GraphPad Software, San Diego, CA, USA). Statistical significance was determined by a value of $p \leq 0.05$. Written consent was obtained from all patients, and the guidelines of the Declaration of Helsinki were followed.

\section{Results}

Thirty-six consecutive patients (31 males, five females; mean age $=64.7$ years, range $=40-86$ years $)$ underwent microvascular flap reconstruction following head and neck tumor ablation. A total of 29 RFF and 10 ALT procedures were performed to reconstruct the defects. Two patients underwent a second freeflap transfer due to recurrence. One patient underwent a second free-flap procedure following flap loss. Squamous cell carcinoma was the most frequent histological diagnosis, while the oral cavity was the most frequent site of reconstruction in both groups. The patients' demographic and clinical data are listed in Table I.

The microsurgical success rate was $97 \%$ for the RFF group and $90 \%$ for the ALT group. Re-exploration, classified as major flap complication, was needed in three cases treated with RFF and in three cases treated with ALT, with one total flap loss in each group.

Minor flap complications (Table II) were observed in 23 cases of the RFF group and in nine cases of the ALT, and included dehiscence, infection, hematoma, congestion, seroma, and partial flap loss, all generally more frequent in the RFF group.

Donor-site complications occurred in 10 cases of RFF and in four cases of ALT (Table III). Dehiscence was the most frequent donor-site complication (five cases in the RFF group and two in the ALT group).

Systemic complications were experienced by seven patient of the RFF group and three of the ALT patients, and consisted of respiratory failure in two, aspiration pneumonia in three, and cardiopulmonary failure in two patients of the RFF group; hypoxemia in two and edema in one patient of the ALT group. Perioperative mortality was observed in two cases, one in each group, due to hypoxemia and respiratory failure complicated by encephalitis.

There was no statistical significant difference between the two groups regarding donor-site complications, major flap complications, minor flap complications or systemic complications (Table IV). However, there was a trend towards a higher flap re-exploration rate in the ALT group compared to the RFF group $(p=0.162$, relative risk $=0.35$, $95 \%$ confidence interval $=0.1-1.4)$.

\section{Discussion}

The RFF and ALT are two types of free-flaps that are frequently used for complex reconstruction after tumor ablation in the head and neck region (15-24). Microsurgical outcomes, donor-site and systemic complications should be the main factors influencing the selection between RFF and ALT. In order to determine the advantages and disadvantages of each flap type, we performed a retrospective study on 36 patients with large defects in the head and neck area who underwent reconstruction with either RFF or ALT after cancer extirpation. However, the main limits of this analysis were the low number of patients included and the unequal distribution of patients between the two groups.

Previous investigations supposed a correlation between the microsurgical outcomes and the practicability of flap harvesting and preparation (4). While RFF harvesting is relatively easy to perform, ALT dissection is more difficult, due primarily to the anatomy of the perforator originating from the descending branch of the lateral circumflex femoral artery (4). Our study found no significant difference in terms of microsurgical outcomes expressed as flap survival rates between RFF and ALT, showing that the anatomic variability of ALT perforators did not influence survival rates and demonstrating that the two flaps present analogous reliability, in line with the results achieved by Liu et al. (4).

Surgical re-exploration rates for compromised flaps, considered as major flap complications according to Classen and Ward's classification (13), present large variability in the literature, with reports of between $3 \%$ and $20 \%$ (25-30). Our data indicated a re-exploration rate of $10 \%$ for RFF and of $30 \%$ for ALT flaps, without statistical significant difference between the groups $(p=0.16)$. However, there was a trend towards a higher re-exploration rate in the ALT group, which we supposed to be correlated with the high number of patient that received pre-operative radiation therapy in the small sample analyzed (Table I). In fact, although the majority of studies confirm that radiation therapy does not influence flap survival, many authors reported a reduced clinical success rate in head and neck surgery in the case of prior radiation therapy (31-33).

Systemic medical complications developed in $24 \%$ of the RFF group and in $20 \%$ of the ALT group, without any difference statistically significant, between the two groups $(p=0.83)$. This high rate of complications is in line with the literature and is mainly due to the medical comorbidities of 
Table I. Patient demographic and clinical data.

\begin{tabular}{lrl}
\hline Characteristic & RFF & ALT \\
\hline Gender, $\mathrm{n}$ & 26 & 8 \\
$\quad$ Male & 3 & 2 \\
$\quad$ Female & & \\
Age, years & $65.2(40-86)$ & 63.3 (40-79) \\
$\quad$ Mean (range) & & \\
ASA score, $\mathrm{n}$ & 0 & 0 \\
I & 13 & 6 \\
II & 15 & 4 \\
III & 1 & 0 \\
IV & & \\
Recipient site, $\mathrm{n}$ & 17 & 6 \\
Oral cavity & 9 & 2 \\
Oropharynx & 3 & 2 \\
$\quad$ Midface & & \\
Preoperative radiation therapy, $\mathrm{n}$ & 3 & 5 \\
$\quad$ Yes & & \\
Pathological diagnosis, $\mathrm{n}$ & 27 & \\
Squamous cell carcinoma & 1 & \\
Liposarcoma & 1 & \\
Adenocarcinoma &
\end{tabular}

ASA: American Society of Anesthesiologists.

Table II. Minor flap complications in the patient groups treated using anterolateral thigh flap $(A L T)$ and radial forearm flap $(R F F)$.

\begin{tabular}{lcc}
\hline Minor flap complication & RFF (n) & ALT (n) \\
\hline Skin graft loss & 0 & 0 \\
Infection & 4 & 2 \\
Hematoma & 3 & 2 \\
Seroma & 3 & 0 \\
Dehiscence & 9 & 2 \\
Congestion & 1 & 1 \\
Partial flap loss & 3 & 2 \\
\hline Total & 23 & 9 \\
\hline
\end{tabular}

$\mathrm{n}$ : Number of instances.

Table III. Donor-site complications in the patient groups treated using anterolateral thigh flap $(A L T)$ and radial forearm flap $(R F F)$.

\begin{tabular}{lcc}
\hline Complication & RFF (n) & ALT (n) \\
\hline Seroma & 0 & 0 \\
Hematoma & 0 & 0 \\
Infection & 1 & 1 \\
Dehiscence & 5 & 2 \\
Congestion & 2 & 0 \\
Skin graft loss & 3 & 0 \\
Total & 10 & 4 \\
\hline
\end{tabular}

n: Number of instances.
Table IV. Comparison by statistical analysis between the patient groups treated using anterolateral thigh flap $(A L T ; n=10)$ and radial forearm flap $(R F F ; n=29)$.

\begin{tabular}{lrlll}
\hline Complication & $\begin{array}{r}\text { RFF, } \\
\mathrm{n}(\%)\end{array}$ & $\begin{array}{c}\text { ALT, } \mathrm{n} \\
(\%)\end{array}$ & $\begin{array}{c}\mathrm{RR} \\
(95 \% \mathrm{CI})\end{array}$ & $p$-Value \\
\hline Donor site & $10(5.7)$ & $4(6.7)$ & $0.86(0.28-2.6)$ & 0.76 \\
Major flap & $3(10.3)$ & $3(30)$ & $0.35(0.1-1.4)$ & 0.162 \\
Minor flap & $23(13.2)$ & $9(15)$ & $0.88(0.44-1.78)$ & 0.83 \\
Systemic & $7(24.1)$ & $2(20)$ & $0.88(0.44-1.78)$ & 0.83 \\
\hline
\end{tabular}

RR: Relative risk, CI: confidence interval.

patients (34). Eckardt et al. recommended a proper and critical preoperative evaluation of the risk of post-operative complications as being essential before selection for extensive oncological and reconstructive surgery, as the majority of the patients with head and neck tumors present medical comorbidities $(35,36)$. In our series, the majority of patients were classified as ASA 2 or 3, with one patient classified as ASA 4, with equal distribution of pre-operative risk between the two groups (Table I).

Our study found no significant difference in terms of donor-site complications, with an overall rate of $6 \%$ for RFF group and $7 \%$ for ALT group $(p=0.76)$. Many surgeons have focused on the donor sites of flaps, seeking to obtain optimal functional and an esthetic reconstruction without causing significant harm to the region of the donor flap (8). A growing body of research has recently described the advantages of the ALT donor site $(10,37$ 39). The study by Valentini et al. highlighted that the donor defect can, in most cases, be closed directly, without causing a noticeable scar, with minimal morbidity (10). Several authors have supported the idea that the RFF is most associated with donor-site morbidity and esthetic deformity $(8,10,40,41)$. In a comparative investigation, Loreti et al. indicated the ALT as an ideal soft-tissue flap in oral reconstruction, with functional results comparable to those of the RFF at the receiving site but with the additional advantages of minimal donor-site morbidity and a high level of patient satisfaction (9). Others have supported the belief that there is no difference. Novak et al. compared the two flaps regarding donor-site morbidity, finding that the majority of patients of both groups were not bothered by scar appearance, light touch, numbness or pain, and no significant difference was found regarding donor-site morbidity (11). Although our series has the limitation of having only a small number of cases, unequally distributed, we support the idea that complications at the donor site cannot indicate the selection of the best reconstructive technique between the two flaps. 


\section{Conclusion}

In conclusion, our study showed that both RFF and ALT free flaps are reliable reconstructive options in head and neck after cancer extirpation. We observed that microsurgical outcomes, such as free-flap survival and complications, donor-site morbidity and systemic complications do not appear to differ significantly after ALT or RFF reconstructions. Individual patient factors and expertise of the surgeon should therefore be the determinants of the selection of the best reconstructive option (11).

\section{Conflicts of Interest}

None.

\section{Founding}

None.

\section{References}

1 Wong $\mathrm{CH}$ and Wei FC: Anterolateral thigh flap. Head Neck 32: 529-540, 2010 .

2 Kim EK, Evangelista M and Evans GR: Use of free tissue transfers in head and neck reconstruction. J Craniofac Surg 19: 1577-1582, 2008.

3 Lutz BS and Wei FC: Microsurgical workhorse flaps in head and neck reconstruction. Clin Plast Surg 32: 421-430, 2005.

4 Liu WW, Li H, Guo ZM, Zhang Q, Yang AK, Liu XK and Song M: Reconstruction of soft-tissue defects of the head and neck: Radial forearm flap or anterolateral thigh flap? Eur Arch Otorhinolaryngol 268: 1809-1812, 2011.

5 Yang G, Chen B and Gao Y: Forearm free skin flap transplantation. Natl Med J China 61: 139-141, 1981.

6 Song R, Gao Y, Song Y, Yu Y and Song Y: The forearm flap. Clin Plast Surg 9: 21-26, 1982.

7 Soutar DS and McGregor IA: The radial forearm flap in intraoral reconstruction: The experience of 60 consecutive cases. Plast Reconstr Surg 78: 1-8, 1986.

8 Huang $\mathrm{CH}$, Chen $\mathrm{HC}$, Huang YL, Mardini S and Feng GM: Comparison of the radial forearm flap and the thinned anterolateral thigh cutaneous flap for reconstruction of tongue defects: an evaluation of donor-site morbidity. Plast Reconstr Surg 114: 1704-1710, 2004.

9 Loreti A, Di Lella G, Vetrano S, Tedaldi M, Dell'Osso A and Poladas G: Thinned anterolateral thigh cutaneous flap and radial fasciocutaneous forearm flap for reconstruction of oral defects: comparison of donor site morbidity. J Iral Maxillofac Surg 66: 1093-1098, 2008.

10 Valentini V, Cassoni A, Marianetti TM, Battisti A, Terenzi V and Iannetti G: Anterolateral thigh flap for the reconstruction of head and neck defects: alternative or replacement of the radial forearm flap? J Craniofac Surg 19: 1148-1153, 2008.

11 Novak CB, Lipa JE, Noria S, Allison K, Neligan PC and Gilbert RW: Comparison of anterolateral thigh and radial forearm free flap donor site morbidity. Microsurgery 27: 651-654, 2007.
12 Saklad M: Grading of patients for surgical procedures. Anesthesiol 2: 281-284, 1941.

13 Classen DA and Ward H: Complications in a consecutive series of 250 free flap operations. Ann Plast Surg 56: 557-561, 2006.

14 Tarsitano A, Pizzigallo A, Sgarzani R, Oranges CM, Cipriani R and Marchetti C: Head and neck cancer in elderly patients: is microsurgical free-tissue transfer a safe procedure? Acta Otorhinolaryngol Ital 32: 371-375, 2012.

15 Koshima I, Fukuda H, Yamamoto H, Moriguchi T, Soeda S and Ohta S: Free anterolateral thigh flaps for reconstruction of head and neck defects. Plast Reconstr Surg 92: 421-428, 1993.

16 Koshima I: Free anterolateral thigh flap for reconstruction of head and neck defects following cancer ablation. Plast Reconstr Surg 105: 2358-2360, 2000.

17 Lin DT, Coppit GL and Burkey BB: Use of the anterolateral thigh flap for reconstruction of the head and neck. Curr Opin Otolaryngol Head Neck Surg 12: 300-304, 2004.

18 Lueg EA: The anterolateral thigh flap: Radial forearm's "big brother" for extensive soft-tissue head and neck defects. Arch Otolaryngol Head Neck Surg 130: 813-818, 2004.

19 Lutz BS, Wei FC, Chang S, Yang KH and Chen IH: Donor site morbidity after suprafascial elevation of the radial forearm flap: A prospective study in 95 consecutive cases. Plast Reconstr Surg 103: 132-137, 1999.

20 Neligan PC, Mulholland RS, Irish J, Gullane PJ, Boyd JB, Gentili F, Brown D and Freeman J: Flap selection in cranial base reconstruction. Plast Reconstr Surg 98: 1159-1166, 1996.

21 Song YG, Chen GZ and Song YL: The free thigh flap: A new free flap concept based on the septocutaneous artery. Br J Plast Surg 37: 149-159, 1984.

22 Varvares MA, Cheney ML, Gliklich RE, Boyd JM, Goldsmith T, Lazor J, Baron JC and Montgomery WW: Use of the radial forearm fasciocutaneous free flap and montgomery salivary bypass tube for pharyngoesophageal reconstruction. Head Neck 22: 463-468, 2000.

23 Webster HR and Robinson DW: The radial forearm flap without fascia and other refinements. Eur J Plast Surg 18: 11$16,1995$.

24 Zuidam JM, Coert JH and Hofer SO: Closure of the donor site of the free radial forearm flap: A comparison of full-thickness graft and split-thickness skin graft. Ann Plast Surg 55: 612-616, 2005.

25 Zafero ME, Weber RS, Lewin JS, Roberts DB and Hanasono MM: Complications and functional outcomes following complex oropharyngeal reconstructions. Head and Neck 32: 1003-1011, 2010.

26 Bianchi B, Copelli C, Ferrari S, Ferri A and Sesenna E: Free flaps: outcomes and complications in head and neck reconstructions. J Craniomaxillofac Surg 37: 438-442, 2009.

27 Jones NF, Johnson JT, Shestak KC, Myers EN and Swartz WM: Microsurgical reconstruction of the head and neck: interdisciplinary collaboration between head and neck surgeons and plastic surgeons in 305 cases. Ann Plast Surg 36: 37-43, 1996.

28 Devine JC, Potter LA, Magennis P, Brown JS and Vaughan ED: Flap monitoring after head and neck reconstruction: evaluating an observation protocol. J Wound Care 10: 525-529, 2001.

29 Simpson KH, Murphy PG, Hopkins PM and Batchelor AG: Prediction of outcomes in 150 patients having microvascular free tissue transfers to the head and neck. Br J Plast Surg 49: 267273, 1996. 
$30 \mathrm{Wu}$ CC, Lin PY, Chew KY and Kuo YR: Free tissue transfers in head and neck reconstruction: Complications, outcomes and strategies for management of flap failure: analysis of 2019 flaps in single institute. Microsurgery 34: 339-344, 2014.

31 Kruse AL, Luebbers HT, Grätz KW and Obwegeser JA: Factors influencing survival of free-flap in reconstruction for cancer of the head and neck: a literature review. Microsurgery 30: 242248, 2010.

32 Bengtson BP, Schusterman MA, Baldwin BJ, Miller MJ, Reece GP, Kroll SS, Robb GL and Goepfert H: Influence of prior radiotherapy on the development of postoperative complications and success of free tissue transfers in head and neck cancer reconstruction. Am J Surg 166: 326-330, 1993.

33 Schultze-Mosgau S, Grabenbauer GG, Radespiel-Troger M, Wiltfang J, Ries J, Neukam FW and Rodel F: Vascularization in the transition area between free grafted soft tissues and preirradiated graft bed tissues following preoperative radiotherapy in the head and neck region. Head Neck 24: 42-51, 2002.

34 Farwell DG, Reilly DF, Weymuller EA Jr., Greenberg DL, Staiger TO and Futran NA: Predictors of perioperative complications in head and neck patients. Arch Otolaryngol Head Neck Surg 128: 505-511, 2002.

35 Pohlenz P, Klatt J, Schön G, Blessmann M, Li L and Schmelzle R: Microvascular free flaps in head and neck surgery: complications and outcome of 1000 flaps. Int J Oral Maxillofac Surg 41: 739-743, 2012.

36 Eckardt A, Meyer A, Laas U and Hausamen JE: Reconstruction of defects in the head and neck with free flaps: 20 years experience. Br J Oral Maxillofac Surg 45: 11-15, 2007.
37 Chana JS and Wei FC: A review of the advantages of the anterolateral thigh flap in head and neck reconstruction. Br J Plast Surg 57: 603-609, 2004.

38 Demirkan F, Chen HC, Wei FC, Chen HH, Jung SG, Hau SP and Liao CT: The versatile anterolateral thigh flap: a musculocutaneous flap in disguise in head and neck reconstruction. Br J Plast Surg 53: 30-36, 2000.

39 Wolff KD, Kesting M, Thurmüller P, Böckmann R and Hölzle F: The anterolateral thigh as a universal donor site for soft-tissue reconstruction in maxillofacial surgery. J Craniomaxillofac Surg 34: 323-331, 2006.

40 Timmons MJ, Missotten FE, Poole MD and Davies DM: Complications of radial forearm flap donor sites. Br J Plast Surg 39: 176-178, 1986.

41 Chen CM, Lin GT, Fu YC, Shieh TY, Huang IY, Shen YS and Chen $\mathrm{CH}$ : Complications of free radial forearm flap transfers for head and neck reconstruction. Oral Surg Oral Med Oral Pathol Oral Radiol Endod 99: 671-676, 2005.
Received March 29, 2018

Revised April 25, 2018

Accepted May 3, 2018 